\title{
Editorial
}

\section{Breastfeeding - still not reaching the target}

We have had consensus for many years over the importance of breastfeeding for optimal health of mother and child. However, the promotion of breastfeeding is slow and no country reaches the recommendation of exclusive breastfeeding for 6 months even for $50 \%$ of the population of mothers.

\section{European progress just too slow}

In this issue of the journal, a couple of papers have been picked out to highlight the topic, reflecting the situation in Europe and Ireland in particular. The paper by Cattaneo et al. ${ }^{(1)}$ points to the problem of European countries still not having implemented a common breastfeeding monitoring system. When a few countries are compared from 2002 to 2007, some progress can be found in initiation, exclusivity and duration of breastfeeding, but still Europe is nowhere near the recommended levels. In Sweden and Norway, where breastfeeding initiation is very high, exclusive breastfeeding at 6 months is about $12 \%$ and $7 \%$, respectively, while in the UK it is $3 \%$. The highest prevalence of exclusive breastfeeding at 6 months postpartum in 2007 was $42 \%$, reported from the Slovak Republic, followed by $33 \%$ reported by Latvia.

Why is progress so slow? Cattaneo et al. ${ }^{(1)}$ in this issue point to the importance of pre-service training, solid maternity protection and a prompt and strong follow-up of the WHO International Code of Marketing of Breastmilk Substitutes.

\section{Policy makers - shape up!}

What on earth is wrong with European policy makers? Has the extremely strong case for breastfeeding still not succeeded in reaching those in power? It seems fairly simple to set up a strategy to monitor breastfeeding - why do we have a recommendation if we do not bother to create a proper surveillance system? We wrote about the same issues in this journal ${ }^{(2-4)}$ in 2001 and 2005, as a follow-up of the EuroDiet report and of the European Breastfeeding promotion project, both financed by DG Health and Consumers in the European Commission.

\section{Irish breastfeeding}

Ireland was pointed out as a country where the initiation of breastfeeding was extremely low in the paper published in
$2005^{(5)}$, as well as at the launch of the Blueprint for Action for promotion of breastfeeding in Europe, which took place in Dublin 2004. We are now happy to see two papers in this issue from Ireland. The first one looks at the prevalence and determinants of breastfeeding initiation and duration in a sample of women in Ireland. Tarrant et al. ${ }^{(5)}$ took a crosssectional sample of mothers in Dublin, 401 Irish nationals and forty-one non-Irish nationals. Out of these mothers, only $47 \%$ of the Irish mothers and almost $80 \%$ of the non-Irish mothers initiated breastfeeding. The determinants for initiation of breastfeeding were age over 35 years, well-educated mothers with a supportive partner and a positive antenatal decision to breastfeed. A major barrier for breastfeeding was that some mothers thought it was an embarrassing way to feed an infant.

In the second Irish paper in this issue, Holmes et al. ${ }^{(6)}$ discuss the association between breastfeeding and anthropometry and CVD risk factors later in life, from the Young Hearts Project, Northern Ireland. Those who had been breastfed were significantly taller than the not breastfed while there was no other siginificant difference in anthropometry, blood pressure or lipid profile. The comparison here was between having been breastfed at all and nonbreastfed. The authors conclude that taller height is associated with improved life expectancy and therefore the results do support a beneficial effect of breastfeeding.

If a higher prevalence of exclusive breastfeeding had existed here, other differences may have been possible to identify. Out of the 101 children who were breastfed, twenty-eight were breastfed for less than 1 month and another forty for only 1-3 months.

\section{Burkina Faso prevention of HIV, exlusive breastfeeding and safe alternatives}

The last paper selected within the breastfeeding focus for this month is a paper from Burkina Faso, regarding the difficulties of providing appropriate replacement feeding for mothers with HIV. The study investigated the implementation and assessment of a pilot initiative to provide food support for the period 6-12 months postpartum when mothers had opted for exclusive breastfeeding for 6 months in order to reduce mother-to-child transmission of HIV. The project showed that without the food support programme, many of these mothers would not have been able to provide appropriate replacement feeding. Hence, food security for infants needs to be addressed in HIV programmes striving to prevent mother-to-child transmission. ${ }^{(7)}$ 


\section{A clear need for action}

Considering the massive differences in initiation rates of breastfeeding across Europe, it would be extremely interesting to study clinical procedures and routines around birth and how these have changed over time. The Baby-Friendly Hospital Initiative is still moving forwards, introducing the ten steps towards successful breastfeeding in maternity clinics. Clinical routines in birth clinics underwent a rapid and dramatic change in the late $1960 \mathrm{~s}$ and 1970s in Sweden and Norway, introducing initiation of breastfeeding as a natural part of the delivery, a change in clinical procedure which also led to a massive improvement in initiation rates in those countries.

We need to explain the importance of breastfeeding better to our decision makers, who have obviously not heard or not understood, since supporting measures are still lacking. Breastfeeding is nature's continued process of providing tailored nourishment, closeness and protection against infections to infants after birth. We tend to forget that we are mammals.

Agneta Yngve

Editor-in-Chief

Marilyn Tseng

Deputy Editor

\section{References}

1. Cattaneo A, Burmaz T, Arendt $\mathrm{M}$ et al. on behalf of the 'Promotion of Breastfeeding in Europe: Pilot Testing the Blueprint for Action' Project (2010) Protection, promotion and support of breast-feeding in Europe: progress from 2002 to 2007. Public Health Nutr 13, 751-759.

2. Yngve A \& Sjostrom M (2001) Breastfeeding in countries of the European Union and EFTA: current and proposed recommendations, rationale, prevalence, duration and trends. Public Health Nutr 4, 631-645.

3. Yngve A \& Sjostrom M (2001) Breastfeeding determinants and a suggested framework for action in Europe. Public Health Nutr 4, 729-739.

4. Cattaneo A, Yngve A, Koletzko B et al. (2005) Protection, promotion and support of breast-feeding in Europe: current situation. Public Health Nutr 8, 39-46.

5. Tarrant RC, Younger KM, Sheridan-Pereira M et al. (2010) The prevalence and determinants of breast-feeding initiation and duration in a sample of women in Ireland. Public Health Nutr 13, 760-770.

6. Holmes VA, Cardwell C, McKinley MC et al. (2010) Association between breast-feeding and anthropometry and CVD risk factor status in adolescence and young adulthood: the Young Hearts Project, Northern Ireland. Public Health Nutr 13, 771-778.

7. Cames C, Mouquet-Rivier C, Traoré T et al. (2010) A sustainable food support for non-breastfed infants: implementation and acceptability within a WHO mother-to-child HIV transmission prevention trial in Burkina Faso. Public Health Nutr 13, 779-786. 